\title{
Relation between Nasal Septal Deviation and Pneumatization of Mastoid Air Cells - A Computerised Tomographic Study
}

\author{
N. Vinay Kumar ${ }^{1}$, T. S. Gugapriya ${ }^{2}$ \\ ${ }^{1}$ Associate professor, Department of Anatomy, Government Medical College, Palakkad, Kerala. ${ }^{2}$ Professor, Department of Anatomy, All India Institute of \\ Medical Sciences, Nagpur, Maharashtra.
}

\section{Abstract}

Introduction: The environment of middle ear cavity gets regulated mostly by pneumatized mastoid air cell system (MACS). Many theories exist that details the process of pneumatization of this MACS. The nasal septal deviation (NSD) has been shown to be instrumental in influencing pneumatization of paranasal sinuses to varied degrees. The effect of NSD on the pneumatization of MACS remains questionable due to limited literature available. And so this study was done to find the relation between the side of NSD and extent of Pneumatization of MACS on that side by computerized tomographs of Paranasal sinus region. Subjects and Methods: 120 CT images of paranasal region from archives of radiology department were studied for NSD. The NSD was classified according to the nasal septal angle. The extent of pneumatization of mastoid region was studied and classified. The relation between severe NSD and extent of mastoid pneumatization was noted. Results: NSD was found to be right sided in $90 \%$ cases studied and 20, 45, 55 were seen belonging to group I, II and III NSD respectively. The mean NSA was found to be 13.5o. Mastoid region was observed to be hypo pneumatized in the side of NSD in 42 cases of group III NSD. Conclusion: The findings of the study puts forth the need for assessment of NSD and planning possible correction of NSD prior to middle ear and mastoid surgeries for successful results.

Keywords: Nasal septal deviation, Mastoid air cells, Nasal septal angle, Pneumatization

Corresponding Author: Dr. T. S. Gugapriya, Professor, Department of Anatomy, All India Institute of Medical Sciences, 1st Floor, Dean office Building, Government Medical College, Nagpur - 440003, Maharashtra.

Received: November 2018

Accepted: November 2018

\section{Introduction}

A highly cellular posterior extension of middle ear, the mastoid air cell system (MACS) regulates, buffers the fluctuations in pressure and temperature within the middle ear cavity. The mechanism of protective action is directly proportional to the degree of its pneumatization. ${ }^{[1-4]}$ Contrasting hypothesis explaining the pneumatization of MACS do exist. It is said to be either genetically mediated or environmentally induced. ${ }^{[1]}$

Studies have proposed a linear increase in degree of pneumatization with age. ${ }^{[5,6]}$ Two hypotheses exist that substantiates intra and inter individual variations in the pneumatization of MACS. They being, the genetic theory where pneumatization was claimed to be determined genetically and the environmental theory where the amount of pneumatization was shown to be dependent on the postnatal diseases involving the middle ear. Moreover, enough proof prevails to show even the genetically controlled normal MACS pneumatization can be altered by various environmental factors. ${ }^{[1]}$

An osseo membrano cartilaginous partition that is seldom in midline in the general population divides the nasal cavity. ${ }^{[7,8]}$ There exists $19.79-79 \%$ reporting of nasal septal deviation (NSD) in literature. ${ }^{[8-12]}$ Multitude of factors are being put forward like development, trauma or ethnicity as contributing to NSD.$^{[8,13-15]}$ Normally NSD is asymptomatic, If symptomatic it results in rhinosinusitis. ${ }^{[8-15]}$ Also the air flow dynamics stands altered in NSD on the convex side of deviation. ${ }^{[1,16,17]}$

More over studies had shown the influence of NSD in altering the volume of air sinuses and middle ear pressure on the side of deviation. ${ }^{[1,7,16-18]}$ With the availability of only few studies, there exist a lacuna about the effect of NSD upon MACS pressure and postnatal pneumatization. And so, this study was done to find out the relation between the degree of NSD and extent of pneumatization of MACS.

\section{Subjects and Methods}

The CT images from 120 subjects of both sexes in the age group of 18 to 50 years were collected from the archives of department of radiology and studied retrospectively. The CT images of subjects who presented with NSD were included in the study. Those images of the subjects with middle ear 
diseases, congenital ENT anomalies, other nasal pathologies and previous history of sino nasal, middle ear or mastoid surgeries were excluded from the study.

The CT scan of the PNS and mastoid region done were continuous sections of $2.0 \mathrm{~mm}$ slice thickness and acquired at $120 \mathrm{kv}, 240 \mathrm{~mA}$ by using GE CT machine. The images stored as DICOM file were imported to RADIANT DICOM viewer for study analysis.

The coronal images of PNS showing maximum deviation were used to determine the side and degree of NSD defined as nasal septal angle (NSA). The side was identified as right or left. The NSA was measured by drawing two lines, the first line from superior attachment of nasal septum at crista galli to the inferior attachment of septum at maxillary crest/ anterior nasal spine and the second one from the point at crista galli to the maximum deviated point on the convex side of the septum. The angle formed between the two lines at the crista galli was measured using RADIANT DICOM viewer.

Based on the NSA measurements, the subjects with NSD were grouped as

- Group I ( $<90$, mild) [Figure 1],

- Group II ( $>9$ o and $<150)$ [Figure 2] and

- Group III (>15o) [Figure 3] according to Elahi et al's grading system. ${ }^{[19]}$

Axial CT images were used for evaluating MACS pneumatization. The presence of air cells in relation to three lines drawn at the level of sigmoid sinus at 450 inclination based on Hans et al method, ${ }^{[20]}$ was done on the side of NSD and grouped into

- Hypo pneumatization - Few Mastoid air cells seen more anterior to the anterior line [Figure 4].

- Moderate pneumatization - Pneumatization seen extending in between first and second lines [Figure 5].

- Good pneumatization - Pneumatization extending beyond middle line [Figure 6].

- Hyper pneumatization - Pneumatization beyond the last line extending even posterolaterally [Figure 7].

The study was undertaken after obtaining prior approval from the Institutional Ethical Committee.

\section{Results}

Table 1: Relation between type of NSD and extent of MACS pneumatization

\begin{tabular}{|l|l|l|l|l|}
\hline $\begin{array}{l}\text { Type of } \\
\text { NSD }\end{array}$ & $\begin{array}{l}\text { Hypo } \\
\text { pneumati } \\
\text { zation }\end{array}$ & $\begin{array}{l}\text { Moderate } \\
\text { pneumatiz } \\
\text { ation }\end{array}$ & $\begin{array}{l}\text { Good } \\
\text { pneumati } \\
\text { zation }\end{array}$ & $\begin{array}{l}\text { Hyper } \\
\text { pneumatiza } \\
\text { tion }\end{array}$ \\
\hline Group I & 0 & 13 & 3 & 4 \\
\hline Group II & 4 & 29 & 9 & 3 \\
\hline Group III & 42 & 10 & 2 & 1 \\
\hline Total & $46(38.3 \%)$ & $52(43.3 \%)$ & $14(3.3 \%)$ & $8(6.7 \%)$ \\
\hline
\end{tabular}

Table 2: NSD and NSA in comparison to previous studies

\begin{tabular}{|c|c|c|c|c|c|}
\hline Study & Right NSD & Left NSD & Bilateral deviation & NSA(Mean) & NSA (Range) \\
\hline Lee et $\mathrm{al}^{[1]}$ & $54 \%$ & $46 \%$ & - & - & - \\
\hline 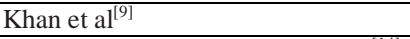 & $36.52 \%$ & $54.78 \%$ & $8.7 \%$ & - & - \\
\hline Prayaga N. Srinivas Moorthy et al ${ }^{[14]}$ & 71 cases & 108 cases & - & - & - \\
\hline Orhan et al ${ }^{[17]}$ & $36.5 \%$ & $63.5 \%$ & - & 12.90 & $5-24.4 o$ \\
\hline Gencer et $\mathrm{al}^{[21]}$ & $54 \%$ & $48 \%$ & - & $14 \mathrm{o}$ & $5-28.10$ \\
\hline Present study & $90 \%$ & $10 \%$ & - & $13.5 \mathrm{o}$ & $5.2-27.4 \mathrm{o}$ \\
\hline
\end{tabular}

\section{CHART 1: PERCENTAGE OF NASAL SEPTAL DEVIATION}

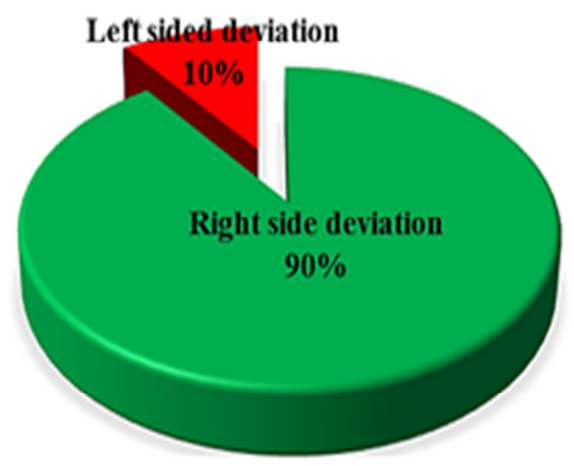

A total of $120 \mathrm{CT}$ scans of 64 males, 56 females in the age group ranging from 18 to 50 years with a mean age of 40.5 years were studied. The side and degree of NSD, and the extent of bilateral pneumatization of MACS were evaluated. In our study, NSD was observed to be predominantly on the right side [Chart 1].
Group I, II, and III NSD were observed in 20, 45 and 55 cases respectively. The NSA ranged from 5.2 o to $27.4 \mathrm{o}$ with a mean of 13.50 .

Evaluation of the extent of MACS pneumatization on the side of NSD showed Hypo pneumatization in Group III NSD mainly. Moderate pneumatization was noted in Group II and I [Table - 1].

\section{CHART 2: COMPARISION OF GRADE I, II, III NSD WITH PREVIOUS STUDIES(\%)}

grade I $\square$ grade II $\mathbf{a}$ grade III

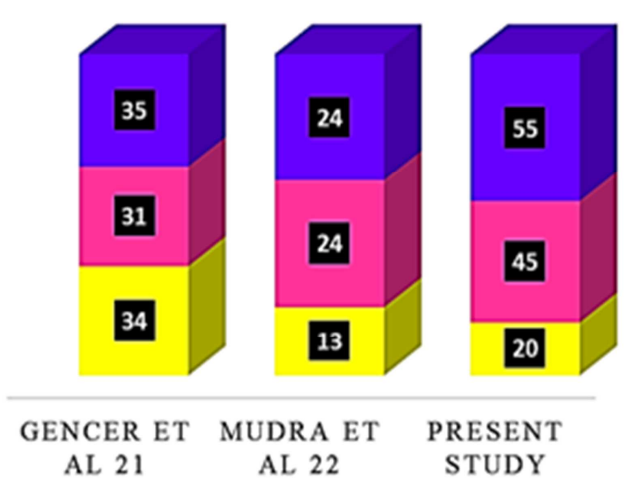



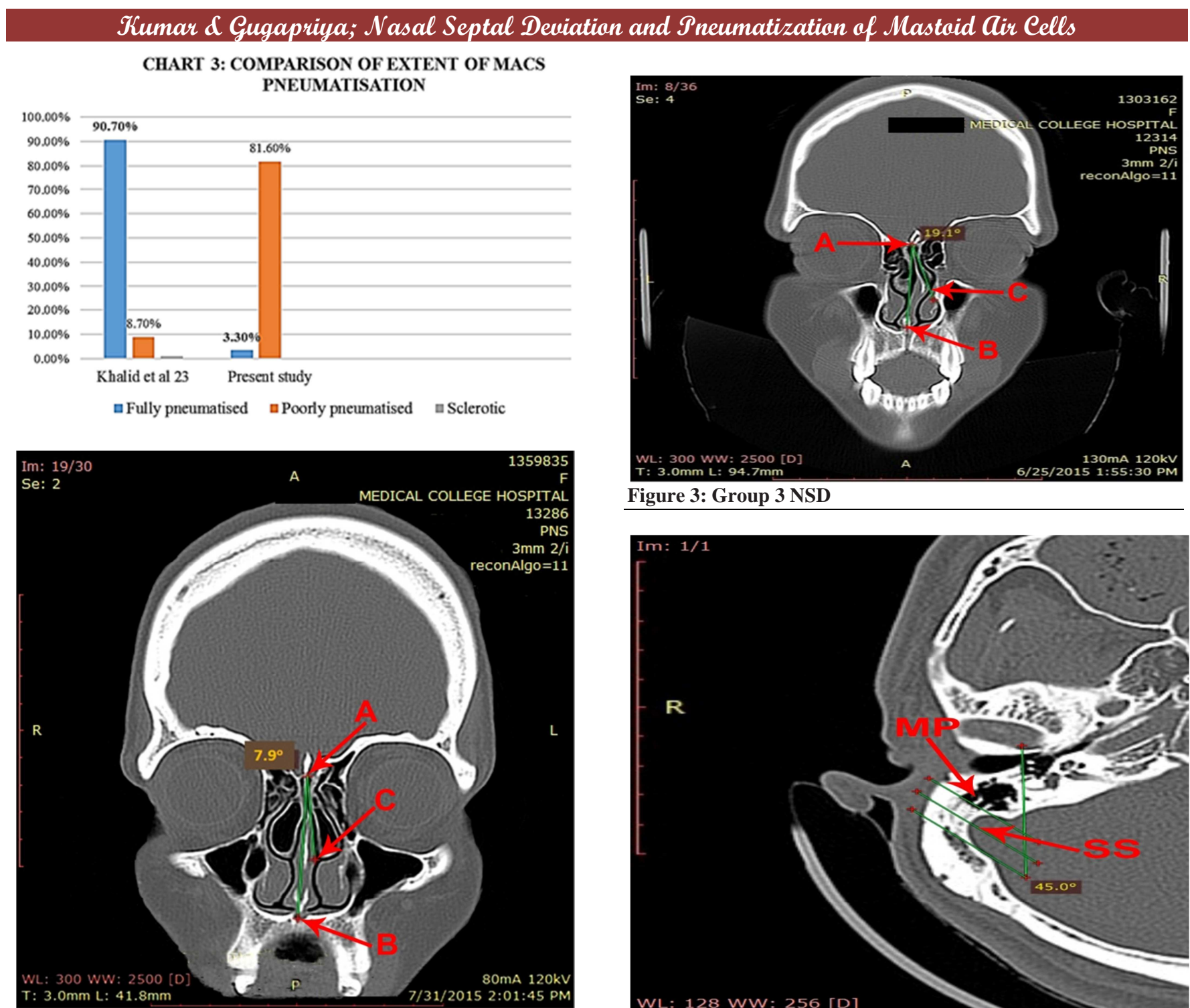

Figure 1: Group 1 NSD. A - junction of nasal septum at crista galli, B - junction of nasal septum at anterior nasal spine/ maxillary crest, $\mathrm{C}$ - maximum deviated point on convex side of septum.

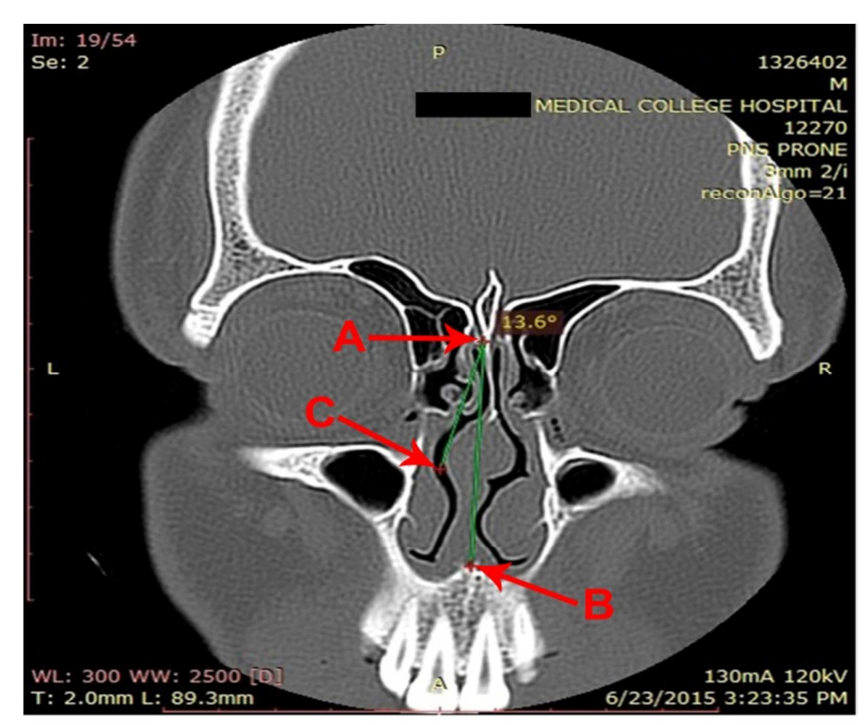

Figure 2: Group 2 NSD.

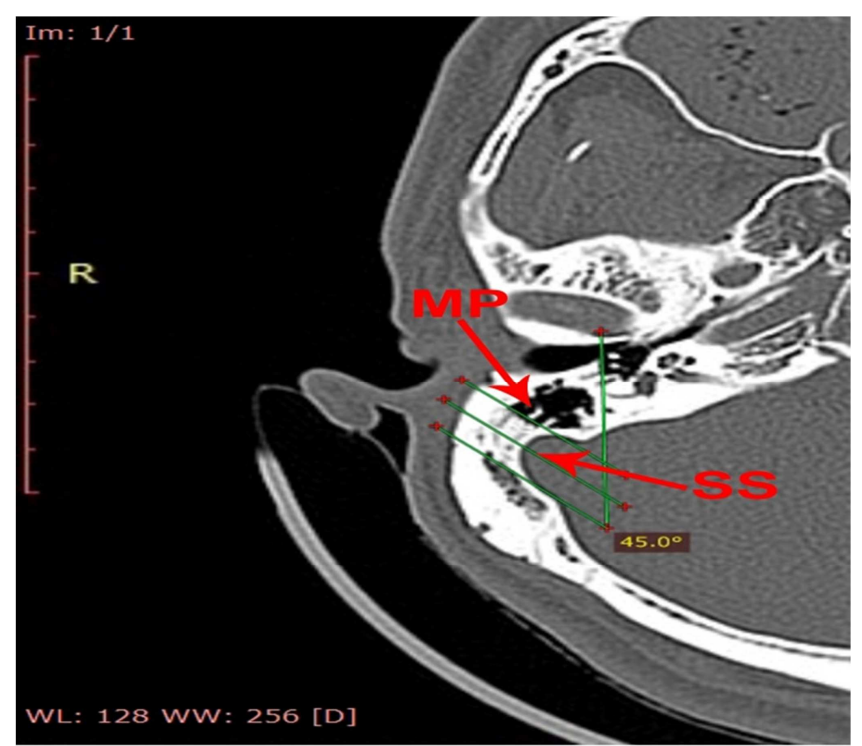

Figure 4: Hypo pneumatisation. SS - Sigmoid sinus, MP Mastoid air cell pneumatisation.

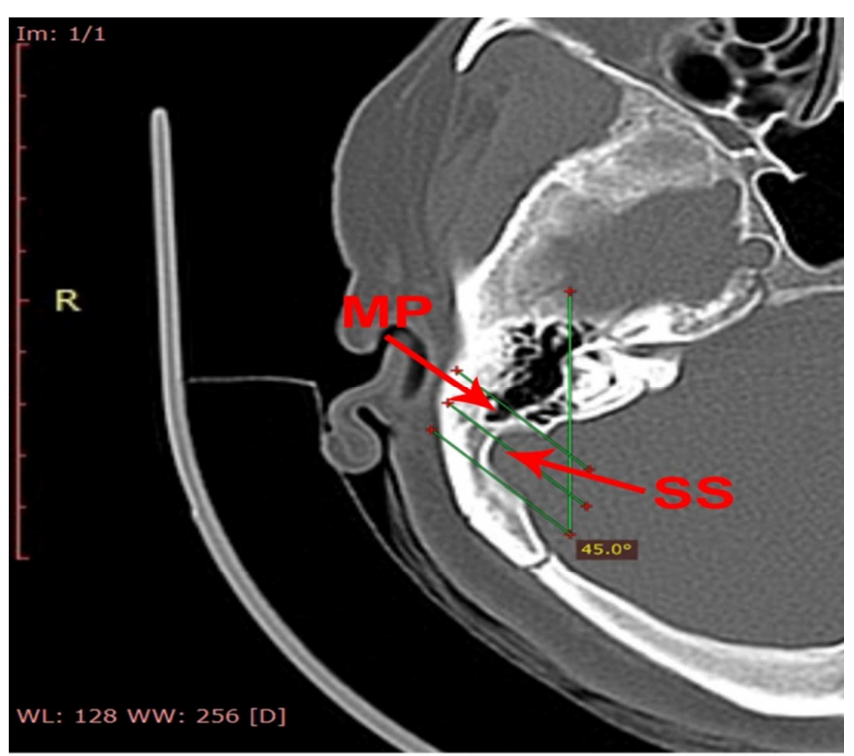

Figure 5: Moderate pneumatisation 

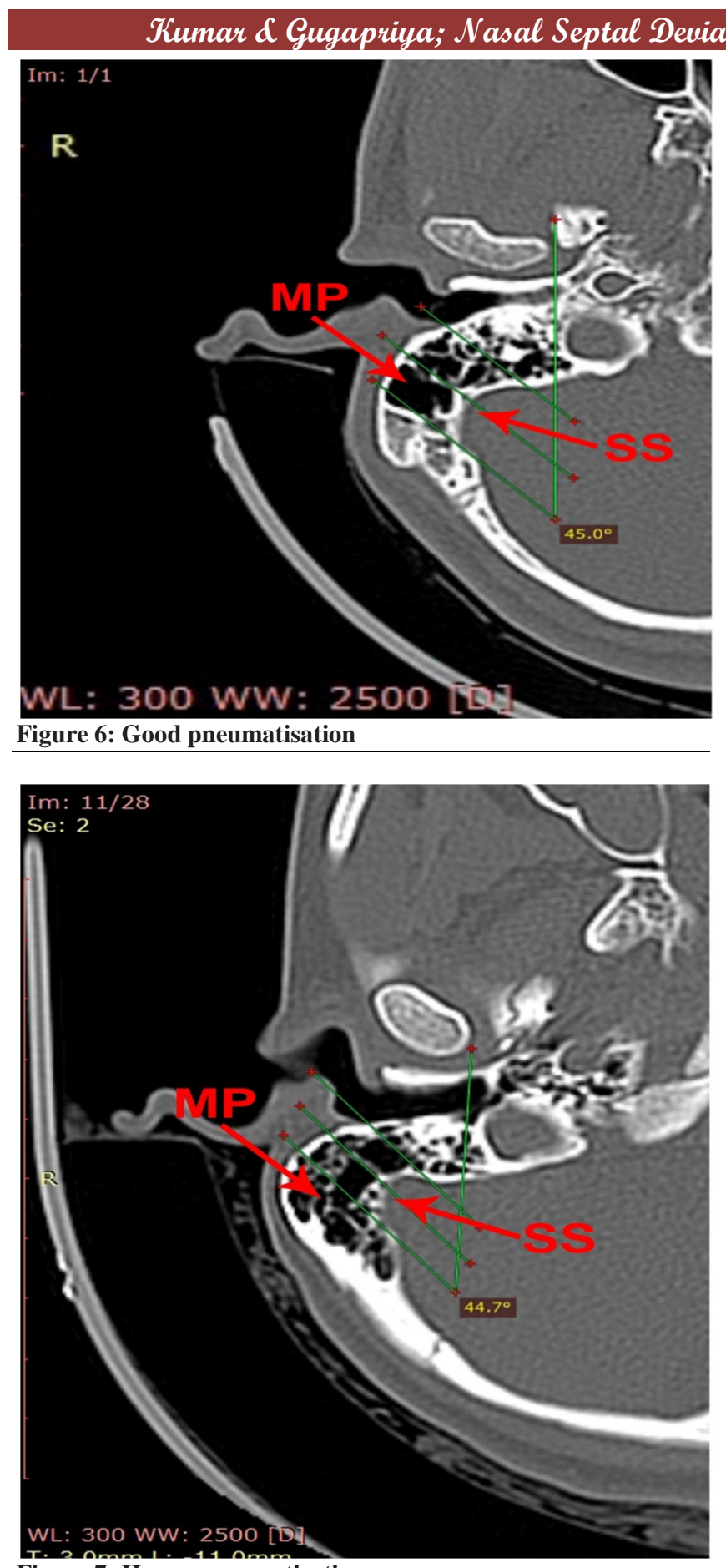

Figure 7: Hyper pneumatisation

\section{Discussion}

The nose has in the midline a septum that helps in equalization of air coursing through each cavity. Nasal aerodynamics stands altered when this septum undergoes deviation of any degree from midline. NSD results in diminished flow of air in the convex side of the septum. ${ }^{[7]}$ NSD was found to be almost equally distributed among the sides and so the right dominance of the present study stands apart from previous studies [Table 2].$^{[9,14,17,21]}$ NSA observed was similar to previously reported studies [Table 2].

The severity of deviation was categorised into three groups and present study observed grade III NSD in increased numbers compared to previous studies [Chart 2].

MACS was claimed to be an independent air reservoir capable of air exchange with middle ear buffering pressure changes occurring there. This action of MACS has been proved to be directly proportional to the extent of its pneumatization in SCUBA drivers. ${ }^{[24]}$

Moreover review studies suggest ethnicity and use of antibiotics to treat ear conditions exert no influence to pattern of aeration and mastoid bone growth pattern. The MACS was shown to develop with antral aeration at birth followed by incremental growth up to 1 year. Following this a linear growth phase happens till 6 years of age and slow incremental phase to adult size which happens around puberty. Even though bone growth and air cell grows in similar pattern, aeration leads bone growth during these phases. ${ }^{[6]}$ Irrespective of race of the study population it was observed that fully pneumatised MACS was the common finding. ${ }^{[23]}$ On contrary, this study found more number of poor to moderate pneumatization [Chart 3].

Elucidation of aeration of MACS aeration with other paranasal aeration showed differing findings. Volume of paranasal air sinuses and mastoid air cells were reported to exhibit positive correlation to age and sidedness. ${ }^{[25]}$ MACS pneumatization was shown to be positively related to sphenoid sinus pneumatization but not with maxillary sinuses. ${ }^{[26]}$

The possible role of NSD in determining the development of MACS has been put forth considering the proximity of opening of both the structures. Distortion of air flow as a result of NSD might be the reason for defective pneumatization of the MACS. ${ }^{[7,16,17,21]}$ Even though NSD could possibly distort the aeration of MACS and other paranasal air sinuses, a definitive correlation was lacking between degree of NSD and aeration of maxillary and mastoid region due to influence of other factors acting in addition to NSD. ${ }^{[1]}$

A correlation between degrees of NSD with MACS volume found decrease in total ethmoid cell volume on the side of NSD. ${ }^{[7]}$ Evaluation of relation between MACS volume and NSD in cases of adult chronic otitis showed larger MACS on the contra lateral side of severe NSD. ${ }^{[21]}$ The occurrence of poor pneumatization on the side of NSD observed in this study also supports similar previous such findings. ${ }^{[1,21]}$

\section{Conclusion}

From being an air reservoir to thermal insulation human MACS plays many a role in the middle ear anatomical and pathological process. The right predominance with increased incidence of Grade III NSD related with decreased aeration of MACS in the side of deviation found in this study stands important to Otolaryngologist. The decision to correct NSD prior to treating middle ear pathologies surgically needs consideration based on this studies positive finding of relation between NSD and extent of MACS pneumatization.

\section{References}

1. Lee DH, Jin KS. Effect of Nasal Septal Deviation on Pneumatization of the Mastoid Air Cell System: 3D Morphometric Analysis of 
Computed Tomographic Images in a Pediatric Population. Int Adv Otol. 2014; 10(3): 251-5.

2. Lima MA, Farage L, Cury MC, Júnior FB. Mastoid surface area-tovolume ratios in adult Brazilian individuals. Braz J Otorhinolar. 2013 Jun 30; 79(4):446-53.

3. Swarts JD, Foley S, Alper CM, Doyle WJ. Mastoid geometry in a cross-section of humans from infancy through early adulthood with a confirmed history of otitis media. Int J Pediatr Otorhi. 2012 Jan 1; 76(1):137-41.

4. Magnuson B. Functions of the mastoid cell system: auto-regulation of temperature and gas pressure. J Laryngol Otol. 2003 Feb; 117(2):99103.

5. Yegin Y, Çelik M, Şimşek BM. The relationship between the degree of the mastoid pneumatization and mean platelet volume. Otolaryngol Open J. 2016; 2(3):87-90.

6. Cinamon U. The growth rate and size of the mastoid air cell system and mastoid bone: a review and reference. Eur Arch Oto-Rhino-L. 2009 Jun 1; 266(6):781-6.

7. Firat AK, Miman MC, Firat Y, Karakas HM, Ozturan O, Altinok T. Effect of nasal septal deviation on total ethmoid cell volume. J Laryngol Otol .2006; 120: 200-4.

8. Gray, L.P. Deviated Nasal Septum. Incidence and Etiology. Annals of Otology, Rhinology, and Laryngology.1978; 87: 3-20.

9. Khan MN, Nath K, Uddin S. A clinical study of deviated nasal septum with special reference to conventional and endoscopic septoplasty. Int J Res Med Sci. 2016 Dec 16; 4(12):5165-71.

10. Min YG, Jung HW, Kim CS. Prevalence study of nasal septal deformities in Korea: results of nationwide survey. Rhinol. 1995; 33(2):61-5.

11. Piere de Oliviera AK, Junior EE, Santos LV. Prevalence of deviated nasal septum in curitiba, Brazil. Otorhinolaryngology Service of Clinical Hospital of federal University. 2005;1-8.

12. Sriprakash V. Prevalence and clinical features of nasal septum deviation: a study in an urban centre. Int J Otorhinolaryngol Head Neck Surg. 2017 Sep 22; 3(4):842-4.

13. Neskey, D., Eloy, J.A. and Casiano, R.R. Nasal, Septal and Turbinate Anatomy and Embryology. Otolaryngol Clin North Am. 2009; 42:193-205.

14. Prayaga N. Srinivas Moorthy, Srikanth Kolloju, Srivalli Madhira, Ali Behman Jowkar. Clinical Study on Deviated Nasal Septum and Its Associated Pathology. Int. J. Oto and Head \& Neck Surg.2014; 3:75-
81 .

15. Thiagarajan B, Arjunan K. Deviated Nasal Septum and its management. A Straight Nasal Septum is rather rare. Webmed Central: ENT Scholar 2012;3(5):WMC003359

16. Kapusuz Gencer Z, Ozkiris M, Okur A, Karacavus S, Saydam L. The effect of nasal septal deviation on maxillary sinus volumes and development of maxillary sinusitis. Eur Arch Otorhinolaryngol .2013; 270: 3069-73

17. Orhan I, Ormeci T, Aydin S, Altin G, Urger E, Soylu E, Yilmaz F. Morphometric analysis of the maxillary sinus in patients with nasal septum deviation. Eur Arch Oto-Rhino-L. 2014 Apr 1; 271(4):727-32.

18. Low WK, Willatt DJ. The relationship between middle ear pressure and deviated nasal septum. Clinical Otolaryngology. 1993 Aug 1; 18(4):308-10.

19. Elahi MM, Frenkiel S, Fageeh N. Paraseptal structural changes and chronic sinus disease in relation to the deviated septum. J Otolaryngol .1997; 26: 236-40.

20. Han SJ, Song MH, Kim J, et al. Classification of temporal bone pneumatization based on sigmoid sinus using computed tomography. Clin Radiol. 2007; 62:1110-08.

21. Gencer ZK, Ozkiris M, Okur A, Karacavus S, Saydam L. The possible associations of septal deviation on mastoid pneumatization and chronic otitis. Otol Neurotol 2013; 34: 1052-7.

22. Mundra RK, Gupta Y, Sinha R, Gupta A. CT scan study of influence of septal angle deviation on lateral nasal wall in patients of chronic rhinosinusitis. Ind. J. Oto and Head \& Neck Surg. 2014 Jun 1; 66(2):187-90.

23. Khalid Hindi, Sarmad Alazzawi ,Rajagopalan Raman ,Narayanan Prepageran , Kartini Rahmat. Pneumatization of Mastoid Air Cells, Temporal Bone, Ethmoid and Sphenoid Sinuses. Any Correlation? Indian J Otolaryngol Head Neck Surg.2014; 66(4):429-436.

24. Koc A. The Role of Mastoid Pneumatization in the Pathogenesis of Tympanosclerosis. J Int Adv Otol. 2012 Oct 1;8(3):

25. Karakas S, Kavakli A. Morphometric examination of the paranasal sinuses and mastoid air cells using computed tomography. Ann Saudi Med 2005; 25: 41-5.

26. Kim J, Song SW, Cho JH, Chang KH, Jun BC. Comparative study of the pneumatization of the mastoid air cells and paranasal sinuses using three-dimensional reconstruction of computed tomography scans. Surg Radiol Anat. 2010; 32: 593-9.

Copyright: ( $)$ the author(s), publisher. Academia Anatomica International is an Official Publication of "Society for Health Care \& Research Development". It is an open-access article distributed under the terms of the Creative Commons Attribution Non-Commercial License, which permits unrestricted non-commercial use, distribution, and reproduction in any medium, provided the original work is properly cited.

How to cite this article: Kumar NV, Gugapriya TS. Relation between Nasal Septal Deviation and Pneumatization of Mastoid Air Cells - A Computerised Tomographic Study. Acad. Anat. Int. 2018;4(2):14-18.

DOI: dx.doi.org/10.21276/aanat.2018.4.2.5

Source of Support: Nil, Conflict of Interest: None declared. 